\title{
Technologies for learning? An actor-network theory critique of 'affordances' in research on mobile learning
}

\author{
Steve Wright ${ }^{\mathrm{a} *}$ and Gale Parchoma ${ }^{\mathrm{b}}$ \\ ${ }^{a}$ School of Health \& Medicine, Lancaster University, Lancaster, UK; ${ }^{b}$ Educational Research, \\ Lancaster University, Lancaster, UK
}

(Received 27 January 2011; final version received 12 September 2011)

\begin{abstract}
How is the link between learner and technology made in mobile learning? What is the value of the concept of 'affordances'? And how does research articulating this concept act to position mobile devices as 'technologies for learning'? This literature review used both unstructured and structured search samples of published research on mobile learning to critically evaluate the prevalence and influence of the concept of the affordances of mobile technologies. Actor-network theory is drawn on as a theoretical lens through which to critically consider how this concept is articulated, and in particular to explore the way it positions and controls mobile devices as technologies for learning. Parallels in contemporary accounts of mobile learning are drawn with classifications of previous discourses around the introduction of computers into schools. An alternative agenda for mobile learning research is suggested with a focus on authentic and informal contexts rather than controlled experiments.
\end{abstract}

Keywords: mobile learning; actor-network theory; affordances

\section{Introduction}

This literature review takes a critical look at how the concept of affordances is a current theme in contemporary research on mobile learning and considers how this concept is used to position mobile devices as 'technologies for learning'. The way the concept of affordances is used in the research literature is then explored and critiqued by drawing on Bigum's (1998) actor-network theory (ANT) informed categorisations of the discursive practices used to position technologies in relation to learning. The methodological approaches that generate this discourse of mobile devices as technologies for learning are explored and the potential for alternative approaches considered.

\section{Defining mobile learning}

Mobile learning has received a lot of critical, theoretical and empirical research attention in recent years. Mobile devices are increasingly ubiquitous and sophisticated and their potential for use in education is described as a 'new paradigm' (Leung and Chan 2003).

*Corresponding author. Email: s.t.wright@lancaster.ac.uk 
Quinn defined mobile learning as "the intersection of mobile computing and e-learning" (2000, 2), a definition that was retained by Orr (2010) in his literature review 10 years on. However, Orr suggests that this may need to be extended to incorporate "mobile recording, imaging, or communication devices" as part of mobile learning $(2010,107)$.

Most definitions include, or frequently focus on, "the use of wireless-enabled mobile digital devices" (Cochrane 2010, 134). But this is challenged by Laouris and Eteokleous, who assert that:

Not only should we not constrain our definition of mobile learning to learning through mobiles, but we must shift focus from device to human. We suggest taking a broader view that accounts for a learner freely moving in his physical (and virtual) environment. $(2005,6)$

In developing a theory of mobile learning, Sharples, Taylor, and Vavoula also contend that "it is the learner that is mobile, rather than the technology" $(2005,4)$. Further work seeks to link these two strands of a focus on the technology or the learner, with Sharples, Taylor and Vavoula offering a definition of mobile learning that combines them wherein mobile learning is "the process of coming to know through conversations across multiple contexts among people and personal interactive technologies" $(2007,231)$. With mobile learning, the learner and device(s) are fundamentally linked.

We now turn to the methodology for the literature search and framing of the critical accounts we draw on to question one of the most prevalent ways this link is made: through the concept of affordances.

\section{Methodology: literature selection and review processes}

The original focus for this literature review was to look for examples of mobile learning initiatives that could inform development of university programmes in health and medicine. As the review of the retrieved literature progressed, several recurrent themes of methodology, discourse, and conclusions emerged - in particular, the widespread use of the concept of 'affordances for learning' for mobile devices. The variation in meaning and imprecision of the term led to further the authors' questioning the validity of this concept and seeking other accounts that problematised its uncritical assertion. However, it was not just the presence of the term but the way it functioned to position mobile devices as 'technologies for learning' that merited further critical consideration.

Fenwick and Edwards' (2010) book on Actor-Network Theory in Education suggested that ANT could provide a useful 'lens' to look through at the literature under investigation. Parellels can be drawn to Fenwick and Edwards' account of Bigum's (1998) classifications of the discourses used to position information technologies as technologies for learning.

Having started from a broad investigation from which recurrent patterns were identified, the next step tested ideas against a sample of the literature with a view to reducing selection bias. A structured, criteria-based literature search was undertaken to consider suppositions. Two criteria were chosen:

- Influence - as indicated by number of citations to see if the articulation of these concepts was influential in the other research in the field. 
- Currency - as indicated by 'most recent' articles to see if these issues had already been addressed such that contemporary research did not continue to unproblematically assert the issues or adopt the approaches under consideration

The ISI Web of Science database was searched using these criteria:

Topic $=$ ("mobile learning" OR m-learning OR mLearning)

Timespan=All Years.

Databases=SCI-EXPANDED, SSCI, A\&HCI, CPCI-S.

This search retrieved 720 articles (a broad set of mobile learning literature across disciplines, which was drawn on for searches on methodologies). Search criteria were then refined by applying the following refinement:

\section{Refined by: Subject Areas=(EDUCATION \& EDUCATIONAL RESEARCH $)$}

This reduced the articles retrieved to 304 with a focus on educational research (excluding more technical approaches from computer science or telecommunications). The results were then sorted by times cited and a sharp tail-off was noted from the most cited article (58 citations) to the 10th (18 times), with a further drop from the 11th onward, suggesting that the 10 most cited articles would provide a sufficient snapshot of influential and widely cited studies. It was also limited as a practical sample alongside the most recent. Had the sample not provided sufficient examples, it could have been expanded.

\section{Step one: the discourse of affordances - speculative, analytic or incoherent?}

Oliver's (2005) extensive examination of the logical and analytical shortcomings of the term 'affordance' concludes that the term is highly problematic in both its origin and in its application. The term originates in Gibson's work on perception (Gibson 1977, 1979), wherein it is proposed that affordances are latent in the environment, objectively measurable and independent of the individual's ability to recognise them, but are always in relation to the actor. However, the nature of this relationship is never fully explained by Gibson and the concept of trying to understand all possible affordances leads to a logical impasse such that trying to measure affordances "becomes speculative rather than analytic" (Oliver 2005, 401).

The term 'affordance' is made more complex by its subsequent appropriation by Norman, who moved from Gibson's supposedly objective 'real affordances' to considering 'perceived affordances' (Norman 1988). This shift incorporates subjective interpretation and mental activity, which were explicitly rejected by Gibson. However, Norman also claims that "affordances reflect the possible relationships among actors and objects" $(1988,10)$ - with 'possible' leading to the same unresolved impasse as Gibson's position. Further echoing Gibson, Norman extends this claim asserting that his affordances "are properties of the world" $(1988,10)$. This leads Oliver to conclude that "'affordance' becomes redundant as an analytic concept" (2005, 406).

Despite its positivistic origin, unclear usage and logical inconsistencies, affordance is both a prevalent and persistent term in the literature on mobile learning. It appears in Cochrane (2010), Cochrane and Bateman (2010), Herrington and 
Herrington (2007), Koole (2006), Lai et al. (2007), Orr (2010), Sharples et al. (2009) and Traxler (2010), among others. The term frames a key literature review (Orr 2010) and is used in one of the 10 most cited papers (Liang et al. 2005) and one of the 10 most recent articles (Cochrane and Bateman 2010).

Contentions around origin and validity aside, the use of the term affordance is highly inconsistent. One paper states that as "the primary affordance of mobile learning is that since the devices are small they can be carried anywhere, learning is available to the user in a ubiquitous fashion" (Orr 2010, 108). However, in research focusing on the evaluation of mobile devices for distance learning, the affordances of laptops and even desktops are considered (Koole and Ally 2006; Koole, 2006). Another author uses the term 'affordance' as synonymous with technical features, listing "mobile-specific affordances, such as GPS tagging, and built-in cameras" (Cochrane 2010, 134) or "the affordances of mobile Web 2.0 technologies: connectivity, mobility, geolocation, social networking, personal podcasting and vodcasting, etc." (Cochrane and Bateman 2010, 4). These 'affordances' are then mapped directly to the enactment of constructivist pedagogy.

Oliver challenges such use, asking:

Does it matter, however, if the term is used inconsistently, if it is productive? Arguably, yes. For researchers, incoherence in terminology will provide a false impression of research coherence, hiding (not resolving) problems. $(2005,411)$

The mapping and articulation of affordances does more, however, than merely propose "simple causal relationships" (Oliver 2005, 411) between technological device and use - it constructs and positions the device in a particular discursive way, as a technology for learning. By considering these discourses themselves as the level of analysis, rather than searching or categorising properties of the devices, Oliver suggests that this allows "technology to be described in a way that recognises its social and historical production, as well as intentionality" $(2005,411)$.

Having considered the problems with the concept of affordances from its origins to its inconsistent use, we now turn to explore Oliver's suggestion of analysing the relationship of technology and human user at the level of discourse. The use, incoherent as it may be, of the concept of 'affordances' articulates a particular discourse about technology. This discourse exists in competition with other rival discourses that differ in their positioning of technology in relation to learning.

\section{Step two: solutions in search of educational problems - how discourses position technologies}

Mobile devices have seen rapid development and adoption in recent years with 'mobile learning' research focusing on their potential use in formal education. Bigum (1998) offers an account of the introduction of computers to schools in Australia, which shows striking similarity to current discourses surrounding the use of mobile devices in formal education.

Bigum's analysis draws on the perspective of ANT. This theoretical framework uses "the metaphor of heterogeneous network ... a way of suggesting that society, organisations, agents and machines are all effects generated in patterned networks of diverse (not simply human) materials" (Law 1992, 380). These heterogeneous human/non-human networks require "“symmetrical analysis,' a principle which holds 
that the material and non-human elements of any network should be treated analytically in the same way as the social and human elements" (Fox 2005, 102). The intention of undertaking an ANT-informed analysis or perspective is then "to elucidate how any network grows in influence and/or contracts - the analytical interest is to illuminate the processes, rather than explain end results" (Fox 2005, 102).

Bigum focuses on the discourses in use by different groups to describe the computer, and notes "the dependence ... on an essentialist account of computer technology" (1998, 588). He 'clusters' the discourses into four categories, which he assigns on the basis of "the characteristic ideas of a discursive set, a signature rather than an average position" (Bigum 1998, 588).

He posits four dominant discourses:

(1) 'Boosters': "The most visible and dominant set of discourses (that) position computers as 'learning' technologies - artefacts to learn with, to learn through, and to learn about."

(2) 'Anti-schoolers': A subgroup of booster discourses wherein "the computer still is identified as a learning technology, but it is ascribed such importance and significance that less efficient knowledge technologies such as schools no longer have a role to play."

(3) 'Critical': these discourses are less unified and represent "a broad set of concerns" and see "the computer as politics by another name". There is concern with access, equality and potential for emancipation.

(4) 'Doomsters' are a subset of the critical discourses and, like the 'anti-schoolers', they "recognise the computer for its capacity to bring about epochal change and are strongly opposed to it." (Bigum 1998, 588-93)

These categories are all evident in contemporary discourses surrounding mobile devices in education and can be seen as opposing camps or sides of a coin: boosters versus critical, and anti-schoolers versus doomsters.

Anti-schooler discourses are clearly present with reference to mobile technologies in the 'digital natives' writings of Prensky (2001) and Tapscott (2008), heralding "the demise of the University" (Tapscott 2009).

Critical discourses have likened such 'anti-schooler' (or in this case, 'antiuniversity') discourses to a moral panic about the future of the university (Bennett, Maton, and Kervin 2008). They can be seen in literature on issues of disruption (Herrington and Herrington 2007) or the "massive problem" of focus (Goth, Frohberg, and Schwabe 2006, 1). Critical discourses manifest themselves around questions of access to mobile technologies and their expense and potential for exclusion.

Discourses are often displayed as the opposing position. In the booster discourses there are direct references to opposing categories that can be challenged. The critical discourse is presented thus:

For many teachers it is easier to prohibit the use of these 'disruptive' technologies than to risk the illicit use of communication methods that they themselves are unable to understand or detect in use. (Herrington and Herrington 2007, 3) 
Newspaper articles on mobiles being used to cheat in examinations (Williams 2010) carry the implicit "nostalgia for practices and institutions associated with print technology" (Bigum 1998, 593) of the doomsters.

Where research asserts 'affordances for learning', the concept of affordance is used to position these devices as 'technologies for learning'. In one account these affordances are not only asserted as enacting constructivist pedagogies (as reported in Evans 2008), but another step is taken to map device capabilities to constructivist learning and teaching approaches.

We now turn to further consideration, illustration and critique of three of the most dominant themes in literature around mobile learning that represent the 'booster' category.

\section{Step three: problematising the 'booster' discourses}

\section{Booster discourse one: the affordance of anytime/anywhere learning?}

The most common claim of mobile learning 'boosters' is that it enables "educational content anytime, anywhere on any device" (Smyth 2005, 1) or "learning anytime everywhere" (Attewell and Savill-Smith 2009). The proposition that mobile devices enable "anytime, anywhere" learning is broadly claimed (Chen, Kao, and Sheu 2003, 351; Cochrane 2010, 134; Cochrane and Bateman 2010, 3; Frohberg 2007, 3; Herrington and Herrington 2007, 3; Koole 2006, 21; Laouris and Eteokleous 2005, 1; Leung and Chan 2003, 76; Orr 2010, 109; Pfeiffer et al. 2009, 188; Shih and Mills 2007; Traxler 2010, 152).

The term becomes shorthand, causally 'afforded' by the technologies and presented as obvious and inherent. Rendering something as complex as the idea of anytime anyplace learning in this way closes it to investigation; it simply becomes a black box with an input of access, which occurs anytime or anywhere, and an output of learning. What is going on inside the black box has been obscured from view and closed from enquiry. What happens if we open up this black box and consider what is going on? In undertaking the second stage of the literature review, this process was examined by retrieving and reading the articles on mobile devices. Accessing peer-reviewed literature is an activity central to higher education practices of research and academic writing for students and staff. Envisaging higher education learning, teaching or assessment without peerreviewed literature having a significant role is highly problematic. The assertions in the mobile learning literature of anytime, anyplace learning through mobile devices imply this is an affordance of using a mobile device to accomplish this task.

The authors tested the capacity of their own mobile devices (an iPhone and an HTC Desire) to accomplish this scenario: to access peer-reviewed literature from a university library database in which both authors have institutional membership and to which mobile access is claimed to be provided. While we found it possible, on numerous attempts access failed. Often a network was dropped, authentication failed, a document failed to download completely, the device lost power (challenging the notion of any time), remote Internet access was not available, the screen limited legibility and readability, or it was impossible to read in bright sunlight (challenging the assertion of anywhere). Latour (2005) asserts that it is these moments of breakdown that help to render the complex network of human and non-human objects that are acting visible, and open the black box 
that 'affordance' obfuscates. The focus on symmetrical analysis requires us to look equally at the human and non-human elements: both technological and institutional.

\section{'Booster' discourses two: 'ubiquity and prevalence' versus controlled devices and contexts}

Another key discursive theme within the 'booster' discourses that position mobile devices as 'learning technologies' is the assertion of their ubiquity and prevalence. Articles frequently cite sales and survey data for their widespread use in their population of interest and the world at large - often in contrast to lower ownership of computers (Valk, Rashid, and Elder 2010, 118; Sharples, Taylor, and Vavoula 2007, 224). Hand in hand with ubiquity is the heterogeneity of mobile devices with different capabilities. However, rather than making ubiquity and heterogeneity central to investigations and developments, they are frequently excluded from or controlled in the research process.

Much of the literature is based on accounts of small-scale innovations and pilot projects. The most-cited article (58 citations in Web of Science) concerns "a mobile learning system for scaffolding bird watching learning" (Chen, Kai, and Sheu 2003, 1), and adopts a quasi-experimental approach comparing groups of school-aged learners using either a book or a custom-built application on a PDA selected by the researchers and given to groups of participants. Pre-test and posttest results comparing PDA and book group performance is assessed and the mobile group are found to have "improved their learning, above and beyond what would normally be expected" (Chen, Kao, and Sheu 2003, 358). This "successful experiment' - the most-cited paper - is not only illustrative of a booster discourse in itself, but also represents a particular experimental approach, advocating intentional control and issuing of a selected mobile device by the researchers. Other examples include giving students a standardised mobile 'smart' phone (Cochrane 2010), a PDA (Smørdal and Gregory 2003), PDA along with a plug-in camera (Lai et al. 2007), a tablet PC (Attewell and Savill-Smith 2009), a portable DVD player (Pfeiffer et al. 2009) or a multi-functional "eSchoolbag" (Chang, Sheu, and Chan 2003). Of the 10 most-cited papers in the structured search, nine are examples of such small-scale pilot projects where the device used in the study is preselected by the researchers.

There is an issue of incompatibility here as one of the central tenets of the booster discourse for the learning potential of mobile devices is their ubiquity and prevalence in learners' lives. However, studies that report experimental 'proofs' of learning, and subsequent research projects that cite these experimental studies, are marked by the control of the device and exclusion of the participants' own devices.

A notable exception in the 10 most-cited papers is that from Evans (2008), who looks at 'podcasting.' Audio-recordings of lectures or revision notes were made available for download to be played on a portable MP3 player (a mobile phone or dedicated device). In this study, "the students were not provided with any special equipment to access the podcast episodes" (Evans 2008, 494). However, once ubiquity is embraced in practice, instead of seeing the purported affordances of mobile devices for enacting constructivist pedagogies (as reported in Evans 2008, 494, Figure $1, \mathrm{p} 79$ ), there is a return to the didactic pedagogy of transmission from lecturer to learner. Herrington and Herrington critique this, noting: 
It can be argued that the current use of mobile devices in higher education (essentially content delivery) is pedagogically regressive. Their adoption is following a typical pattern where educators revert to old pedagogies as they come to terms with the capabilities of new technologies. $(2007,4)$

This represents a substantial challenge, even a refutation, of the assertions of affordances for learning and affordances for constructivist pedagogies. Once prevalence and ubiquity are expanded to include and acknowledge heterogeneity, the supposed 'affordances' start to break down and its black box begins to crack revealing a much more complex system than a mapping of affordance as input to pedagogy as output.

What is completely lacking to date in mobile learning research is a focus on this ubiquity and prevalence in practice, which ethnographic accounts could provide. The larger sample of 720 articles retrieved by the topic-only search (without refining by subject area for educational research) was revisited. Searching within these results across multiple disciplines, the term 'ethnograph", (using the wild card '*' to search for ethnography, ethnographic, etc.) in topic or keywords retrieved only one article mentioning ethnography. This was a study of mobile applications for language learning, which adopted "an ethnographic approach to research ... to investigate how learners relate to these technologies on a more personal and social level in their everyday lives" (Ros i Solé, Calic, and Neijmann 2009, 42). While the researchers sought to "observe what patterns of behaviour [they] could glean from language learners' use of MP3 devices ... and to document the mundane activities in which learners engage" (Ros i Solé, Calic, and Neijmann, 2009, 41), they still provided the learners with a pre-selected MP3 recording and playback device rather than looking at how the learners used their own 'ubiquitous' devices.

\section{Step three: discussion - desperately seeking mobile learning in practice}

That the bulk of mobile learning research to date is at compulsory school or undergraduate level poses significant issues for its applicability in academic inquiry, postgraduate education and professional development. Here the learning focus becomes more closely connected to professional practices - however, how mobile devices are used within these practices is not in evidence.

Informal learning is notable in its absence, and a call for attention here is echoed in the literature. Frohberg's comprehensive literature review of 120 mobile learning projects included only eight in informal contexts, leading to his call that "learning in informal contexts is another omitted chance of mobile learning" (2007, 10). He notes that:

The majoritarian proportion of adult learning happens informal [sic]. Despite these facts, there are astonishingly few projects dealing with informal learning. (Frohberg 2007, 6)

Within minimal literature that does consider informal learning is Vavoula's (2005) study, which is the most widely cited. Vavoula used a quantitative approach to analysing participants' learning diaries and included working with laptops as an example of 'mobile learning'. However, by looking at only 15 people who all had "a special interest in education and [technology-based] learning" (Vavoula 2005, 17), it is debatable just how 'informal' this learning was or whether it was more 
akin to professional development rather than the "majoritarian proportion" Frohberg considers.

Two other widely used terms in the mobile learning literature are 'communities of practice' and 'situated learning'. A full consideration of these frameworks is outside the scope of this paper, but consideration of their origins serves to develop this line of reasoning. Communities of practice came from the close study of situated learning in practice: Vai and Gola tailors in West Africa (Lave 1996), ships' quartermasters (Lave and Wenger 1991) and medical insurance claims processors (Wenger 1998) all occurring outside mainstream education or training. For mobile learning research to simply refer to communities of practice, or attempt to set them up to support a controlled pilot project, is to miss a key inspiration and potential of this body of theory - to focus on learning in practice and the tools used, rather than seeking to set up and control for the device, situations and practices and connect them via 'affordances'.

A focus on situated practices suggests an ethnographic approach whereby the context and practices are observed without seeking to control them. Undertaking such research is not a trivial undertaking: mobility challenges traditional practices of ethnographic study and new approaches are both needed and suggested (Höflich and Hartmann 2006), which requires stepping outside the literature of educational research and embracing other contemporary accounts of mobile device usage.

Where else should we look for such a project? We must first move away from the essentialist positioning of these devices as 'learning technologies' and acknowledge instead that they are:

Developed and designed for various retail niches and corporate markets, certainly not for learning, however informal. This should not be a surprise; educational technology has always been parasitic, originally co-opting desktop computers intended for corporate business customers and now trying to co-opt mobile devices intended for individual lifestyle customers. (Traxler 2010, 150)

Students today are accessing online courses from mobile devices. This is mobile learning happening in practice without institutional control of the device or context, but with a pressing need to understand who, when and how access is occurring. Projects to explore this creatively through looking at students' everyday use of technologies, rather than specifically focusing on 'mobile learning' (see, for example, Jones, 2010), can give greater insight into situated practice compared with controlled quasi-experimental innovations.

Engeström makes a similar call in his consideration of "wildfire activities", noting that educators "tend to define top down the desirable patterns of mobility we want our mobile learners to engage in. The risk is that these patterns do not touch what is going on in the lives of the learners" $(2009,2)$. Engeström's inquiry suggests that a focus on diverse situated practices, such as those of skateboarders, bird watchers and disaster relief workers, can provide insights unavailable from controlled studies.

A community that has enthusiastically adopted mobile devices is found within craft brewing. This community spans hobbyists, professional brewers and those on formal higher education programmes (e.g. the MSc in Brewing and Distilling at Edinburgh's Herriot Watt University). Within the craft-brewing community, mobile devices have been enthusiastically adopted and are referred to as being essential for individual learning. For example, one iPhone app has had approximately 350 downloads within a year of its release (Kent Place Software, email communication, 20 
August 2010). However, studies of people who have chosen to use mobile devices in their learning and practice are not in evidence in the literature to date, despite the calls for just such a focus. Instead it is dominated by the top-down imposition of technologies, locales and tools to complete pre-defined tasks.

\section{Conclusion}

The identification of collaborative and competing networks and their characteristic learning patterns, through research, is arguably what networked learning should be about, rather than the design of new utopian cyber-classrooms. (Fox 2001, 89)

This paper has focused on how research findings act discursively to position mobile technologies as technologies for learning. The uncritical use of the contentious and essentialist concept of affordances has been problematised and the way it is articulated within research considered. Using Bigum's classificatory framework of discourse groupings of boosters, anti-schoolers, critical and doomster, these approaches to research have been shown not as a value neutral search for "truth" but instead as discourses that are articulated in opposition to or competition with other discourses seeking to position these technologies in different ways. ANT has the potential to refocus, reframe and problematise over-simplified black boxes of 'affordances for learning'.

We have challenged the assertion that researching and implementing mobile learning is of pressing concern due to the ubiquity and prevalence of the devices. By contrast, in the research literature we have considered, the heterogeneity of these ubiquitous and prevalent devices is obfuscated. Furthermore the devices, practices and locales are controlled. Rather than affording 'progressive' constructivist pedagogies on the rare occasions in the literature that the genie of heterogeneity is unleashed, pedagogical practices have become regressive. Calls for studies of informal learning and examining the use of mobile devices by choice rather than by design have largely gone unheeded.

Some potential areas and sites for research addressing these have been proposed. One of the authors is currently undertaking ethnographic research of situated mobile learning practices among craft brewers.

ANT offers us "a way to intervene, not a theory of what to think" (Fenwick and Edwards 2010, 1) and helps us to unpack taken-for-granted assumptions and consider the process of researching technology from a different perspective. Some of the potential for the application of this theoretical frame has been explored here. In particular, the way research acts to discursively position technologies in relation to learning. It is hoped that this paper will contribute to greater critical consideration of the use of the term 'affordances'. Finally, we hope this paper further contributes to the call for research taking an ethnographic approach to studying mobile learning in authentic, situated practice rather than in settings and with technologies selected and controlled by the researcher.

\section{References}

Attewell, J., and C. Savill-Smith, eds. 2009. Mobile learning anytime everywhere: A book of papers from MLEARN 2004. http://www.voced.edu.au/td/tnc_83.294.

Bennett, S., K. Maton, and L. Kervin. 2008. The 'digital natives' debate: A critical review of the evidence. British Journal of Educational Technology 39, no. 5: 775-86. 
Bigum, C. 1998. Solutions in search of educational problems: Speaking for computers in schools. Educational Policy 12, no. 5: 586-601.

Chang, C.Y., J.P. Sheu, and T.W. Chan. 2003. Concept and design of ad hoc and mobile classrooms. Journal of Computer Assisted Learning 19, no. 3: 336-46.

Chen, Y.S., T.C. Kao, and J.P. Sheu. 2003. A mobile learning system for scaffolding bird watching learning. Journal of Computer Assisted Learning 19, no. 3: 347-59.

Cochrane, T. 2010. Exploring mobile learning success factors. Research in Learning Technology 18, no. 2: 133-48.

Cochrane, T., and R. Bateman. 2010. Smartphones give you wings: Pedagogical affordances of mobile Web 2.0. Australasian Journal of Educational Technology 26, no. 1: 1-14.

Engeström, Y. 2009. Wildfire activities: New patterns of mobility and learning. International Journal of Mobile and Blended Learning 1, no. 2: 1-18.

Evans, C. 2008. The effectiveness of m-learning in the form of podcast revision lectures in higher education. Computers \& Education 50, no. 2: 491-8.

Fenwick, T., and R. Edwards. 2010. Actor-network theory in education. London: Routlege.

Fox, S. 2000. Communities of practice, Foucault and actor-network theory. Journal of Management Studies 37, no. 6: 853-68.

Fox, S. 2001. Studying networked learning: Some implications from socially situated learning theory and actor-network theory. In Networked Learning: Perspectives and Issues, ed. C. Steeples and C. Jones, 77-92. London: Springer-Verlag.

Fox, S. 2005. An actor-network critique of community in higher education: Implications for networked learning. Studies in Higher Education 30, no. 1: 95-110.

Frohberg, D. 2007. Mobile learning is coming of age - What we have and what we still miss. Paper presented at the 4th DELFI Conference, in Darmstadt, Germany. http://www. comp.leeds.ac.uk/umuas/reading-group/MLearn_Framework.pdf.

Gibson, J.J. 1977. The theory of affordances. In Perceiving, acting, and knowing: Toward an ecological psychology, ed. R. Shaw and J. Bransford, 67-82. Oxford: Oxford University Press.

Gibson, J.J. 1979. The ecological approach to visual perception of experimental psychology. Hillsdale, NJ: Lawrence Erlbaum.

Goth, C., D. Frohberg, and G. Schwabe. 2006. The focus problem in mobile learning. Paper presented at the 2006 Fourth IEEE International Workshop on Wireless, Mobile and Ubiquitous Technology in Education, November 16-17, in Athens, Greece.

Herrington, A., and J. Herrington. 2007. Authentic mobile learning in higher education. In Proceedings of the AARE 2007 International Educational Research Conference, ed. P.L. Jeffrey, 1-9. Freemantle, WA: AARE.

Höflich, J., and M. Hartmann. 2006. Mobile communication in everyday life: Ethnographic views, observations and reflections. Vol. 2.0. Berlin: Frank \& Timme.

Jones, C. 2010. Networked learning, the net generation and digital natives. In Proceedings of the 7th International Conference on Networked Learning 2010, ed. L. DirckinckHolmfeld, V. Hodgson, C. Jones, M. de Laat, D. McConnell, and T. Ryberg, 617-8. Aalborg, Denmark: Networked Learning.

Koole, M. 2006. The framework for the rational analysis of mobile education (FRAME) model: An evaluation of mobile devices for distance education. http://auspace.athabascau.ca:8080/dspace/bitstream/2149/612/1/01628461.pdf.

Koole, M., and M. Ally. 2006. Framework for the rational analysis of mobile education (FRAME) model: Revising the ABCs of educational practices. ICNICONSMCL '06: Proceedings of the International Conference on Networking, International Conference on Systems and International Conference on Mobile Communications and Learning Technologies (Washington, DC: IEEE Computer Society Press) 216.

Lai, C.-H., J.-C. Yang, F.-C. Chen, C.-W. Ho, and T.-W Chan. 2007. Affordances of mobile technologies for experiential learning: The interplay of technology and pedagogical practices. Journal of Computer Assisted Learning 23, no. 4: 326-37.

Laouris, Y., and N. Eteokleous. 2005. We need an educationally relevant definition of mobile learning. Paper presented at mLearn 2005 , in Cape Town, South Africa.

Latour, B. 2005. Reassembling the social: An introduction to actor-network theory. Oxford: Oxford University Press.

Lave, J. 1996. Teaching, as learning, in practice. Mind, Culture, and Activity 3, no. 3: 149-64. 
Lave, J., and E. Wenger. 1991. Situated learning: Legitimate peripheral participation. Cambridge: Cambridge University Press.

Law, J. 1992. Notes on the theory of the actor-network: Ordering, strategy, and heterogeneity. Systemic Practice and Action Research 5, no. 4: 379-93.

Leung, C-H., and Y-Y. Chan. 2003. Mobile learning: A new paradigm in electronic learning. In Proceedings of the 3rd IEEE international conference on advanced learning technologies, ed. V. Devedzic, J. Spector, D. Sampson, and Kinshuk, 76-80. Athens, Greece: IEEE Computer Society Press.

Liang, J.-K., T.-C. Liu, H.-Y. Wang, B. Chang, Y.-C. Deng, Y.-C. Yang, C.-Y. Chouz, H.-W. Ko, S. Yang, and T.-W. Chan. 2005. A few design perspectives on one-on-one digital classroom environment. Journal of Computer Assisted Learning, no. 21: 181-9.

Norman, D.A. 1988. The psychology of everyday things. New York: Basic Books.

Oliver, M. 2005. The problem with affordance. E-Learning 2, no. 4: 402-13.

Orr, G. 2010. A review of literature in mobile learning: Affordances and constraints. In Proceedings of the 6th IEEE International Conference on Wireless, Mobile, and Ubiquitous Technologies in Education, 107-11. Kaohsiung, Taiwan: IEEE Computer Society Press.

Pfeiffer, V., S. Gemballa, H. Jarodzka, K. Scheiter, and P. Gerjets. 2009. Situated learning in the mobile age: Mobile devices on a field trip to the sea. Research in Learning Technology 17, no. 3: 187-99.

Prensky, M. 2001. Digital natives, digital immigrants. On the Horizon 9, no. 5: 1-6.

Quinn, C. 2000. mLearning: Mobile, Wireless, In-Your-Pocket Learning. LiNE Zine. http:// www.linezine.com/2.1/features/cqmmwiyp.htm.

Ros i Solé, C., J. Calic, and D. Neijmann. 2009. A social and self-reflective approach to MALL. ReCALL 22, no. 1: 39-52.

Sharples, M., M. Milrad, I. Arnedillo Sanchez, and G. Vavoula. 2009. Mobile learning: Small devices, Big issues. In Technology enhanced learning: Principles and products, ed. S. Balacheff, S. Ludvigsen, T. de Long, A. Lazonder, and S. Barnes, 233-49. Heidelberg: Springer.

Sharples, M., J. Taylor, and G. Vavoula. 2005. Towards a theory of mobile learning. Paper presented at mLearn 2005, October 25-28, in Cape Town, South Africa.

Sharples, M., J. Taylor, and G. Vavoula. 2007. A theory of learning for the mobile age. In The SAGE handbook of e-learning research, ed. R. Andrews and C. Haythornthwaite, 221-47. London: Sage Publications.

Shih, Y.E., and D. Mills. 2007. Setting the new standard with mobile computing in online learning. International Review of Research in Open and Distance Learning 8, no. 2: $1-16$.

Smyth, G. 2005. Educational content anytime, anywhere on any device. In Mobile learning anytime everywhere, ed. J. Attewell and C. Savill-Smith, 177-82. London: Learning and Skills Development Agency.

Smørdal, O., and J. Gregory. 2003. Personal digital assistants in medical education and practice. Journal of Computer Assisted Learning 19, no. 3: 320-9.

Tapscott, D. 2008. Grown up digital: How the Net generation is changing your world. New York: McGraw-Hill.

Tapscott, D. 2009. The impending demise of the university. Edge 288. http://www.edge.org/ documents/archive/edge288.html\#tapscott.

Traxler, J. 2010. Students and mobile devices. Research in Learning Technology 18, no. 2: $149-60$.

Valk, J.-H., A.T. Rashid, and L. Elder. 2010. Using mobile phones to improve educational outcomes: An analysis of evidence from Asia. International Review of Research in Open and Distance Learning 11, no. 1: 117-40.

Vavoula, G. 2005. D4.4: A study of mobile learning practices. Report of MOBILearn project. www.mobilearn.org/download/results/public_deliverables/MOBIlearn_D4.4_Final.pdf.

Wenger, E. 1998. Communities of practice. Cambridge: Cambridge University Press.

Williams, R. 2010. Mobile phones drive increase in exam cheating. The Guardian, 3 February. http://www.guardian.co.uk/education/2010/feb/03/exam-cheating-mobile-phone-increase. 